\title{
FORMATION OF METHODOLOGY TO MODEL REGIONAL AIRSPACE WITH REFERENCE TO TRAFFIC FLOWS
}

\author{
Jonas Stankūnas ${ }^{1}$, Vaidotas Kondroška ${ }^{2}$ \\ Vilnius Gediminas Technical University, \\ E-mail:1jonas.stankunas@vgtu.lt; 2vaidotas.kondroska@vgtu.lt (corresponding author)
}

Received 12 July 2012; accepted 20 July 2012

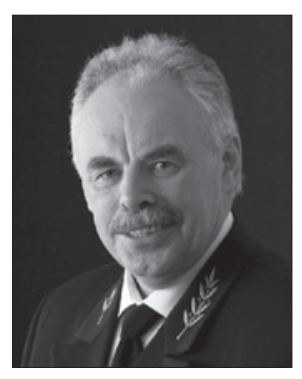

Jonas STANKUNAS, Prof. Dr Habil

Date and place of birth: 1949 in Pakene, Rokiškis District, Lithuania.

Education: 1970 - Krivoj Rog Civil Aviation School, Ukraine; 1976 - Faculty of Automation at Vilnius Institute of Civil Engineering; 1981 - post-graduate studies at Vilnius Institute of Civil Engineering. Affiliations and Functions: 1970-1972 - aviation technician; Vilnius Joint Aviation Platoon: 1972-1975 expert, Radio Apparatus Technology Dept.; 1975-1978 - senior engineer, Scientific Research Sector; 1982-1987 - head of science laboratory of slow wave and deflecting systems, Vilnius Institute of Civil Engineering; 1988-1993 - assoc. professor, Radio Apparatus Technology Department, Vilnius Technical University (formerly Vilnius Civil Eng. Institute) and Kaunas University of Technology (formerly Kaunas Polytechnic institute); since 1993 - director of Antanas Gustaitis Aviation Institute (AGAI) of Vilnius Gediminas Technical University; 1993-1995-assoc. professor; 1995 - habilitated doctor; 1995-1997 professor, Air Traffic Control Department (AGA1); since 1997 - professor, Avionics Department (AGAI); vice chairman of Council of Lithuanian National Aeronautical Technology Platform: delegate of the Republic of Lithuanian at the Specific Program Committee 'Cooperation', theme 'Transport (including Aeronautics)'; member of Advisory Council for Aeronautics Research in Europe (ACARE).

Awards: winner of Lithuanian State Award in Technological Sciences, 1997.

Publications: author or co-author of 143 scientific articles, 4 monographs, 31 reports, 97 scientific reports, and 9 educational methodological publications; inventions: creator or co-creator of 14 inventions; training: advancement training in Great Britain, Canada and Sweden.

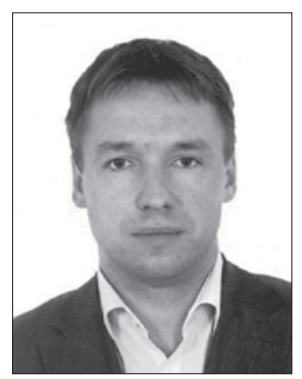

\section{Vaidotas KONDROŠKA}

Date and place of birth: 22 March 1975.

Education: in 1997 graduated an Air Traffic Control studies and acquired a Batchelor's degree in Air Traffic Control and Engineering in the Antanas Gustaitis Aviation Institute of Vilnius Gediminas Technical University. In 1998 graduated Professional Air Traffic Control studies and acquired a Professional degree in Air Traffic Control and Engineering in the Antanas Gustaitis Aviation Institute of Vilnius Gediminas Technical University. In 2000 graduated an Administration and Management of Aviation Enterprises and acquired a Master's degree in Air Traffic Control and Engineering in the Antanas Gustaitis Aviation Institute of Vilnius Gediminas Technical University. 2008-2012 - PhD studies in Transport Engineering. Affiliations and functions: 1997-2006 worked in Joint Stock Company „Gempa“ as director. From 1998 works in SE „Oro Navigacija: 1998-2005 - as an Air Traffic Controller in Vilnius Aerodrome Air Traffic control Center, 2006-2011 - as an Air Traffic Management Development Manager in the Strategic Development Division, from 2011 works as a Deputy Strategic Development director. 2011 also, from 2011 works as an expert in Baltic FAB Programme Management Office. From 2006 works in the Antanas Gustaitis Aviation Institute of Vilnius Gediminas Technical University: 2006-2008 as deputy director for Air Traffic Control, from 2008 works as director of Air Traffic Control Training Unit. Research interest: air traffic management system and airspace management. Publications: author of 9 scientific articles.

\footnotetext{
Abstract. As the number of flights increases, the ATM system, which forms the basis for air navigation services, has to ensure that those flights are not only safe but also effective. Considering the growing impact of traffic flows and
} 
taking into account the not-always-satisfactory indicators of the efficiency of the ATM system, the current ATM system needs changes. Airspace is currently fragmented along national borders, which limits opportunities or even completely prevents the possibility to improve the efficiency of flights, i.e. to perform flights of optimal trajectories and to avoid delays. One of the conditions allowing the current ATM system to become more effective is the amalgamation of the airspace parts or blocks within which (currently in the airspace along national boarders) air navigation services are organised. Comparisons between the ATM systems functioning in different regions of the world show that the less fragmentation there is, the more efficient flights are. One of the main tasks remains, i.e. to establish airspace blocks that meet the expectations of the airspace users.

Keywords: air traffic management, airspace, airspace grids, hierarchical clusterisation.

\section{Introduction}

The air traffic management (ATM) system ensures the safety, efficiency and environmental protection of the aviation transport system. One of the main goals of airspace users is to increase the efficiency of the ATM, i.e. to ensure more direct flight routes, shorter delays (especially when the aircraft is in the air), and the reduction of costs for the services of air navigation that are provided by the system (Pomeret, Mahlich 1997; Voss, Hoffman 2000). The ATM system, as well as all aviation, is unimaginable without airspace, the organisation of which determines how effectively these services are provided.

Since each country has developed and maintains its own ATM system, all the components of this system are developed independently of neighbouring countries or there is only partial exchange of information about current projects and plans.

Comparison of ATM systems in different regions, e.g. in the United States (USA) and in the European region (in the countries of the European Civil Aviation Conference (ECAC)), shows that considerable differences exist in their efficiency (Fron 1998). The current fragmentation of airspace along national borders is one of the major obstacles to ensuring more efficient flights. Air operations are directly influenced by the air traffic management systems of different countries, as well as the organisation of airspace. Evidently, certain individual measures can have a positive impact on ATM systems and at the same time on the increase in flight efficiency, although it would be negligible or local improvement without creating conditions to fundamentally improve the ATM system (McCulloch 1998).

As the number of flights increases, the ATM system, which forms the basis for air navigation services, has to ensure that those flights are not only safe but also effective. Considering the growing impact of traffic flows and taking into account the not-always-satisfactory indicators of the efficiency of the ATM system, the current ATM system needs changes (Mandal, Overend 1996; Kondroška, Stankūnas 2011). Comparisons between the ATM systems functioning in different regions of the world show that the less fragmentation there is, the more efficient flights are. One of the main tasks remains, i.e. to establish airspace blocks that meet the expectations of the airspace users.

This paper examines airspace by using methods that allow the analysed air space to be discretised and that link it with the statistical data of actual flights without relating to the existing elements of the airspace, the distribution of flight control centres, or the navigation aids network, which enables more accurate identification of air traffic flows and the formation of airspace blocks. Due to the different nature of various phases of flight, in order to ensure the accurate detection of airspace blocks, airspace is analysed in two layers, i.e. in the upper airspace and in the lower airspace. After having evaluated the results obtained in both air layers, airspace blocks inherent to the entire airspace are formed by applying clusterisation techniques.

\section{Review of air traffic management system and airspace management and overview of research methods}

After an examination of the expectations of airspace users, as well as the influence of the ATM system and the organisation of airspace on ensuring the efficiency of flights, it was found out that when organising the region-wide airspace, the factors influencing the delay of aircraft, the efficiency of the horizontal flight profile, the efficiency of the vertical flight profile, and the throughput of the ATM system must be taken into consideration (Liang, Chin 1998; Weidner, Green 2000; Kostiuk 2001; Soler et al. 2011).

After an analysis of the efficiency of ATM operation in different regions, it was found out that the ATM system is improved in all regions without any idiosyncrasy and that all the elements of the ATM system could function more optimally. The organisation of the airspace determines the conditions for the operation of the ATM system and the associated efficiency of flights.

It should be noted that the fragmentation of the airspace (mainly along national boarders) could be identified as the main factor limiting the ability to increase the efficiency of flights. The elimination of this limiting factor from the organisation of airspace is important not only to the regions composed of many relatively small 
countries but also to large countries with an airspace structure that cannot create conditions to ensure more effective flights. Certain individual measures can have a positive impact on ATM systems and at the same time increase flight efficiency, but it would be negligible or local improvement without creating conditions to fundamentally improve the ATM system. Only the withdrawal of the current fragmentation can provide the conditions to increase the efficiency of flights (the improvement of throughput and safety, as well as the reduction of costs) of the entire complex both at the regional and local level.

The negative impact of the fragmentation of the airspace shows that it is insufficient to organise airspace at the level of a small area or a single country, and a regional approach is necessary.

Most airspace modelling methods use the airway network as a basis for this analysis (Delahaye et al. 1998; Famanelli 2005; Trandac et al. 2003). As a result of the introduction of new technologies in aviation, more aircraft are flying outside airways, so the use of analytic methods based on the airway network becomes less and less accurate and leads to the use of methods giving priority to the independent organisation of airspace.

It should be noted that the use of a structural weighted lattice would ensure the intended accuracy of air discretisation when applying hierarchical clustering methods, not only to form airspace blocks on the basis of traffic flows in the targeted airspace, but also to ensure the integrity of the airspace and the optimal integration of flight operations.

\section{Methods of analysing space}

Airspace is understood as the physical space in which actual flights are processed. It is advisable to discretise airspace methods independently from the existing airway network. That is done for two reasons. The analysis of the airspace in accordance with horizontal flight operation trajectories leads to a massive amount of data and to cope with such a large amount of data it should be discretised into related components.

Given that by its very nature airspace is connected and its elements are determined according to the global geographic coordinates, airspace is related to the macroscopic space-time domain. This property specifies that all measurements are carried out in a limited space, and the results of the measurements are associated with the global coordinates. Spatial data includes a specific phenomenon connected with three-dimensional observation and measurement. When the target airspace is broken into a lattice, the attachment of flight data to the lattice cell associated with the coordinate system is extremely clear. In this case, each point on the Earth's surface is described by geographical latitude and longitude.
The selection of a structured lattice cell is based on geometric simplicity and the fact that most of the existing calculation procedures use these elements in the approximation of partial differential equations (Thompson et al. 1985). Breaking the target airspace into a lattice (Fig. 1) and thus attributing flights to a corresponding lattice cell means to transform it into the area adjusted for calculation. For space research, regardless of its shape and configuration, especially at regional level, it is appropriate to use rectangular lattice cells. With the use of a rectangular lattice, the network of coordinate line intersections making up its structure ensures a more simplified classification of objects in the target space compared with other forms of lattice cells.

The generation of structured lattice is usually based on n-region $X^{n} c R^{n}$ lattice peaks and the assignment of cells to the reference lattice in whatever standard space $\mathrm{E}^{\mathrm{n}}$ with a certain transformation of $\mathrm{E}^{\mathrm{n}}$ field to $\mathrm{X}^{\mathrm{n}}$ field. $\mathrm{E}^{\mathrm{n}}$ field defines the calculated area:

$$
x(\xi): E^{n} \rightarrow X^{n}, \xi=\left(\xi^{1}, \ldots \xi^{n}\right), x=\left(x^{1}, \ldots x^{n}\right) .
$$

Review of the methods of lattice generation has showed that a structured rectangular lattice is the most appropriate one for the discretisation of airspace.

Algebraic methods of lattice formation are the most appropriate ones to formulate the structured rectangular lattice for discretisation of the target airspace. In addition, before the clusterisation of the weighted lattice cells, it is advisable to divide them into a certain number of classes depending on the number of flights carried out in them in accordance with the data used in the research.

The cluster analysis performs a similar classification of objects into classes. To achieve the specific objectives of the research, it should be projected how the available data or the data obtained during the research will be divided into meaningful units. The main aim of the cluster analysis is to divide different objects into groups (clusters) according to maximum similarity within the group and the greatest differences from other groups.

Most commonly two groups of cluster analysis methods are distinguished: a hierarchical cluster analysis and non-hierarchical cluster analysis. Hierarchical

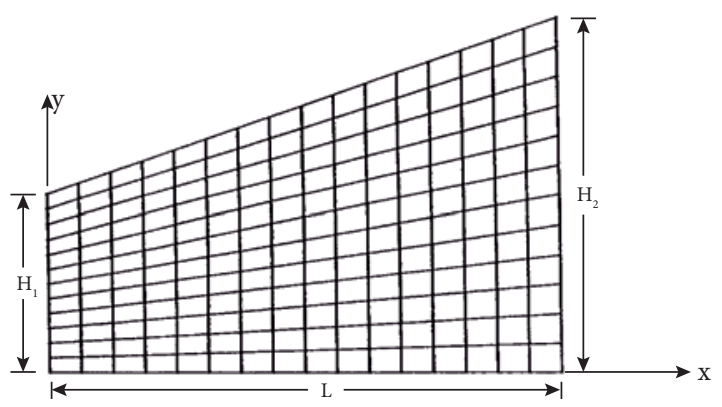

Fig. 1. Computational square region 
cluster analysis methods are the main statistical methods used in forming homogeneous clusters with reference to measured characteristics. With the use of the hierarchical cluster analysis method according to certain rules, isolated clusters are gradually connected until an overall cluster is obtained.

It should be noted that cluster analysis has a lot of specificity and that when different clustering methods are used on the same data, different results may be obtained. Because the proper choice of clustering method may influence the reliability of the results obtained during research, the application of several clustering methods helps to avoid possible errors.

Let us look at classifying objects (or properties) in the absence of training samples.

Given: ${ }^{n}$ objects $O_{1}, O_{2}, \ldots, O_{n}$, whose properties are described in the matrix objects-properties

$$
X=\left[\begin{array}{ccc}
x_{1}^{(1)} & \cdots & x_{n}^{(p)} \\
\vdots & \ddots & \vdots \\
x_{n}^{(1)} & \cdots & x_{n}^{(p)}
\end{array}\right],
$$

or the matrix of proximity between objects

$$
\rho=\left[\begin{array}{cccc}
\rho_{11} & \rho_{12} & \cdots & \rho_{1 m} \\
\rho_{12} & \rho_{22} & \cdots & \rho_{2 m} \\
\cdots & \cdots & \cdots & \cdots \\
\rho_{m 1} & \rho_{m 2} & \cdots & \rho_{m m}
\end{array}\right],
$$

where $x_{i}^{(k)}$ is the $k^{\text {th }}$ property of object $O_{i}$ and $\rho_{i j}$ is the proximity between objects (properties).

The objects-properties matrix is transformed into the matrix of proximity between objects by specifying the size of the proximity between objects according to which the proximity between objects (properties) is calculated.

When region-wide organisation of airspace is conducted, the optimal number of clusters in the target space is not known; it is therefore appropriate to use hierarchical cluster analysis methods. Since the target airspace is discretised into a structural weighted rectangular lattice with each cell defined by its reference point, it is appropriate to use hierarchical algorithms of connection. When these algorithms are used, the initial partition is the following:

$$
S^{(0)}=\left(S_{1}^{(0)}, \ldots, S_{n}^{(0)}\right),
$$

where $S_{i}^{(0)}=\left\{O_{i}\right\}$

$k$ - level partition

$$
S^{(0)}=\left(S_{1}^{(k)}, \ldots, S_{n-k}^{(k)}\right),
$$

obtained from $S^{(k-1)}, k \geq 1$ partition, when combining two classes $\rho\left(\ddot{S}_{1}, \ddot{S}_{2}\right)$

$$
\begin{gathered}
\left(\ddot{S}_{1}, \ddot{S}_{2}\right)=\arg \min S_{1} \neq S_{2} \rho\left(S_{1}, S_{2}\right) . \\
S_{1} S_{2} \in S^{(k-1)}
\end{gathered} .
$$

The final hierarchy is composed of the system of embedded partitions:

$$
S^{0} \subset S^{(1)} \subset \cdots S^{(n-1)} \equiv 0,
$$

which can be graphically displayed. The scheme of this process is depicted in the graph called dendograma (Heller, Ghahramani 2005; Manning, Schütze 1999).

It should be noted that the representation of the clusters obtained is highly important for the correct interpretation of the results obtained (Duran, Odell 1974; Diday, Simon 1976; Michalski et al. 1981).

It is ascertained that the optimal number of FABs in the target airspace can be determined by applying hierarchical clustering methods, and in order to avoid the potential different results of the target airspace due to the application of different cluster analysis techniques, it is advisable to select the two most appropriate methods for airspace analysis since comparison of their results would ensure the identification of the optimal FAB number and form.

\section{Formation of the methodology of modelling regional airspace with reference to traffic flows}

With regard to the strengths and weaknesses of airspace research, it is appropriate to perform the following steps when modelling the research on a regional level:

- determine the target airspace in the horizontal and vertical planes;

- choose the method of discretising the airspace into its constituent parts;

- determine the factors of the 'weight' evaluation for the constituent parts of the target airspace;

- determine the requirements for grouping the constituent cells of the airspace into airspace blocs;

- determine the optimal number of airspace blocks and their boundaries in the target airspace.

This methodology for the organisation of airspace structure covers all major phases of airspace analysis. Transport is a dynamic and rapidly changing area, and therefore scientifically based methodologies enabling effective coordination of strategic goals and the principles of technical and technological implementation must be developed (Baublys, Smičius 2002).

In light of the characteristics of different phases of flight, relatively high density of airports, and special purpose zones (prohibited, dangerous, limited, temporarily isolated, and military) in lower space, it would be appropriate to analyse the airspace in two layers. Referring to the results of the analysis, it is appropriate to choose a threshold of 285 FL. 
To ensure the integrity of the entire airspace and the phases of the flights, applying a unified principle to organise the structure of airspace is proposed firstly to form FABs in the region airspace and then to divide these FABs into airspace of Area Control Centers and Air Traffic Control sectors subsequently (Kondroška, Stankūnas 2012).

Research of airspace organisation has shown that it would be appropriate to rely on the existing air traffic network only in the regions where the air traffic network is very dense and only where it is very close to optimal horizontal flight trajectories. Meanwhile, analysis of discretising the airspace in its constituent volumes is independent of the air traffic network and reflects the actual trajectories of flights.

One of the most accurate methods of discretising airspace is the application of lattices that allow easier and more accurate discretisation of the target airspace. In research, the use of discretisation is becoming more and more frequent. An additional advantage to the application of lattices is that, when this method is used, problems related to the target space boundary investigation can be solved. The generation of the lattice can be defined as a procedure of the orderly distribution of objects in physical space so as to ensure that there are effective relations between objects and that all phenomena can be expressed in the proper accuracy in the integral target space.

By its very nature, airspace is connected and its elements are determined according to global geographic coordinates. Airspace is therefore related to macroscopic space and time domains. This property specifies that all measurements are carried out in a limited amount of space and that the results of the measurements are associated with global coordinates.

What is more, in the proposed methodology, the distribution of lattice cells in the respective weighted classes is projected, and it is proposed to apply not only lattice cells of different sizes, but also a different distribution of the weighted classes for airspace block and regional flight control centres and flight control sectors. One of the main factors is the correspondence with essential traffic flows. After having evaluated the distribution of lattice weighted cells in the target airspace, it would be reasonable to assume that all the lattice cells that perform over 10 flights a day are attributed to the basic flows.

Research has shown that the block of the target airspace is effective if it meets three basic principles:

- makes up a large area, i.e. embraces the airspace of at least two countries;

- corresponds to major traffic flows; and

- ensures the efficient use of the airspace.
In compliance with these basic principles, certain criteria helping to ensure the effectiveness of flights should be applied for FABs being formed in the target airspace. The criteria of three efficiency levels are therefore set for the airspace blocks (basic, optional, and the form of airspace blocks).

The rectangular lattice that is obtained, which is common to both layers of the target airspace, evaluates the features of operations carried out in both layers, and on its basis lattice cell grouping into a certain number of sequences according to the requirements meeting the research purpose is carried out. These sequences will be the basis of the FABs that are formed.

Based on the findings of the work, the cells of the target airspace are divided up with the use of a rectangular lattice; the methodology projects their grouping by using the hierarchical clustering methods.

When airspace blocks are formed after the formation of clusters, their side boundaries must be assured and, if needed, adjusted, ensuring adequate buffer zones for major international airports and military zones. The map of the main international airport areas and military zones is therefore connected with the cluster map that is created and the corresponding corrections, ensuring that airspace block efficiency criteria are fulfilled.

If the results of the airspace blocks that are formed are not satisfactory, the clustering stage is repeated. The airspace design can be fully approved only after testing with an actual air traffic simulator and then actually providing air traffic services (Ehrmanntraut, McMillan 2007).

\section{Formation of airspace blocks in the European region}

This section of the paper provides the experimental research of the application of the methodology for the organisation of the regional air space with reference to the main flows of air traffic.

For the experiments, the airspace of the European region, in which FABs are currently being implemented, was chosen. To test the methodology, actual flight data and the restrictions on the formation of airspace blocks were applied.

To conduct the experiment, a model of the target space was designed and discretised into its constituent parts using a structural square lattice. According to the methodology, the airspace was analysed in two layers. Presently the nine FAB initiatives are being implemented in the European region. In light of this, this analysis resulted in forming from two to nine airspace blocks in the target space and determining the optimal number and configuration of airspace blocks.

To evaluate how the methodology of the organisation of the regional airspace with reference to the main 
air traffic flows and the data of real flights (as proposed in section three) is applied to establish the optimal number of airspace blocks in the airspace of the actual region, the airspace of the European region was selected for the experiment, where, in accordance with the SES concept, FABs are currently being implemented.

Given that in the European region air navigation services are provided to flight level 660 and that according to the Single European Sky, the FABs are supposed to cover the entire airspace of the ATM system, the vertical boundaries of the composed airspace model are from the ground to flight level 660. In the case of the target airspace of the European region, the chosen side of the rectangular region, meant to be divided into lattices, comprises 4400 nautical miles from north to south and 4100 nautical miles from east to west. The coordinates of the central point of the rectangular region are 51'00" north latitude and 2'00" west longitude, and the airspace is analysed in two layers, from ground up to flight level 285 and from flight level 285 up to flight level 660 .

In the rectangular airspace where the structural square lattice of $30 \times 30$ nautical miles was formed, 19.856 lattice cells were created. The space included in the target airspace is several times smaller and consists of 7,357 lattices (Fig. 2).

The results of the research have shown that when distributing the points representing the lattice cells into two, three, four, seven, eight and nine clusters in the target airspace, the most appropriate is Ward's method, and when forming five and six clusters in the target space, the most appropriate is the method of full connection.

Similarly, the distribution of cluster diffusion on the mean (standard deviation) is evaluated, i.e. the smaller the standard deviation of the distribution of clusters, the better the method, since less dispersion around the mean means a more even distribution (more even cluster sizes).

With the clusterisation of the points representing lattice cells into five clusters and the use of the complete-linkage method, the percentage distribution of cluster diffusion on the mean is the lowest $\delta_{\mathrm{Cl}}=3.83$ in case of the target airspace, this is the optimal option (Fig. 3).

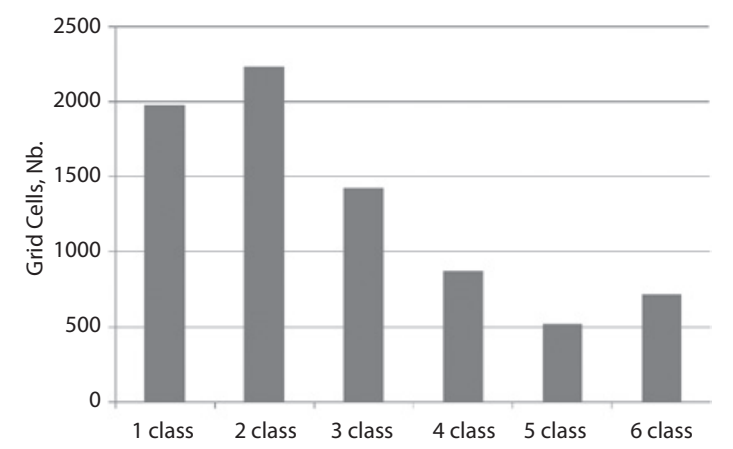

Fig. 2. Distribution of common grid cells

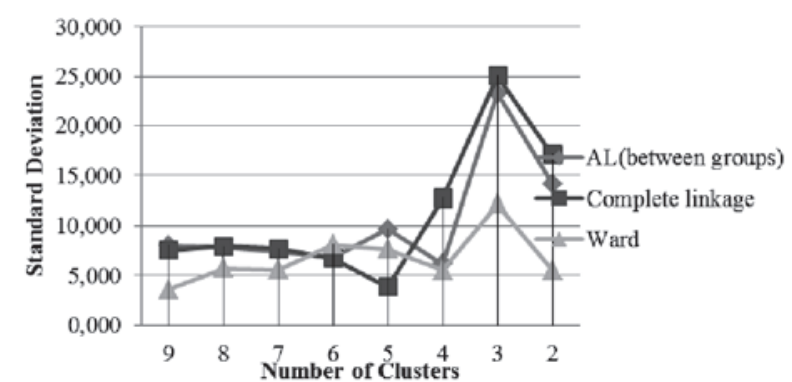

Fig. 3. Comparison of standard deviation of three clustering methods

According to the results of the research, with the use of hierarchical clustering methods to determine the elements of the airspace, it is advisable to apply two methods: the complete-linkage and Ward's methods. The clusters that are formed are balanced according to their sizes, and therefore the FABs formed on their basis enables the successful application of uniform efficiency indicators of their operation.

Since the distribution of military zones in the target region was not evaluated during the clusterisation, the model of the target airspace was complemented by military mapping.

Because of the intensification of traffic flows, the growing demand for airspace, and the introduction of new technologies in the aviation system, it is necessary to reduce the current fragmentation of the airspace and to organise the airspace at a regional level to increase the efficiency of flights. A project to consolidate the airspace in the European region is currently being implemented on the basis of political agreements. In order to adapt the methodology for the organisation of the regional airspace, a model of the target airspace was designed.

Research has shown that in the optimal case, five clusters are formed in the target European region ac-

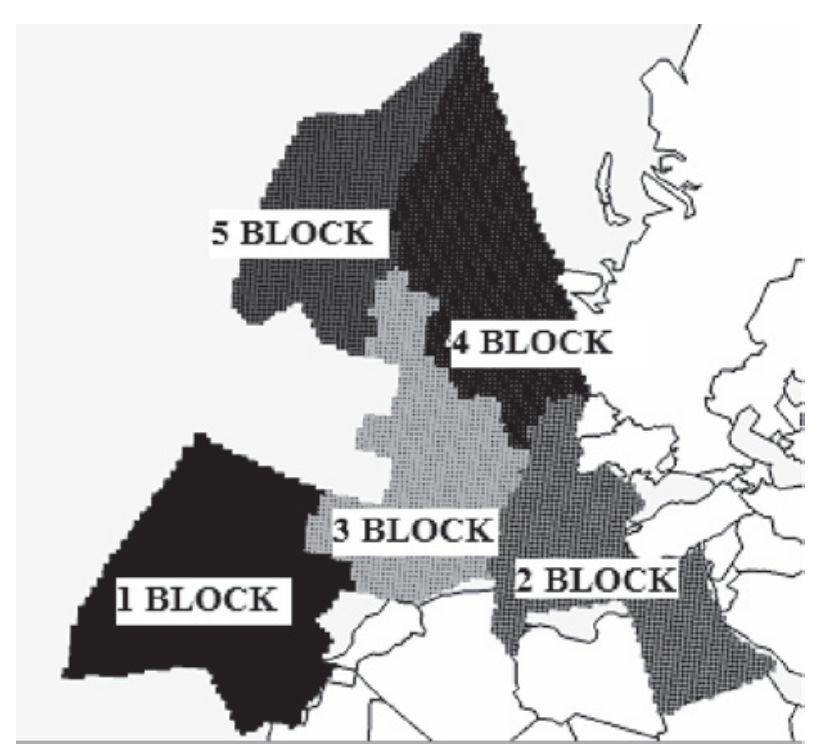

Fig. 4. Optimal airspace blocks in the region analysed 
cording to the established cluster constraints. Based on the methodology, airspace blocks are obtained by adjusting cluster boundaries with regard to the distribution of the military zones in the target region (Fig. 4).

\section{Conclusions}

1. It was determined that the main reason for the lack of efficiency of the ATM system is airspace fragmentation along national borders.

2. In order to ensure the integrity of the airspace and the individual elements of the ATM system, it is proposed to start the organisation of the airspace with the formation of airspace blocks, which subsequently would be distributed to regional air traffic control centres and air traffic control sectors.

3. It was determined that the proposed methodology of modelling the airspace with reference to air traffic flows can be best realised by applying an independent air space discretisation method, structural square weighted lattice, and hierarchical clustering methods.

4. It was determined that the proposed methodology successfully solves the problem of modelling the regional airspace.

The results show that with the use of the proposed methodology of modelling the regional airspace with reference to air traffic flows for the formation of airspace blocks in the regional airspace, the optimal number of airspace blocks in the target region can be determined and that their boundaries can be defined by evaluating the distribution of certain military zones in the region.

\section{References}

Baublys, A.; Smičius, A. 2002. Models of freight transport system development, Transport 17(6): 205-218.

Delahaye, D.; Schoenauer, M.; Alliot, J-M. 1998. Airspace sectoring by evolutionary computation, in Proceedings of the 1998 IEEE International Conference on Evolutionary Computation. IEEE, May 4-9, 1998, 218-223.

Diday, E.; Simon, J. C. 1976. Clustering analysis, in K. S. Fu (Ed.). Digital Pattern Recognition. New York: Springer-Verlag, 47-94.

Duran, B. S.; Odell, P. L. 1974. Cluster Analysis: A Survey. New York: Springer-Verlag.

Ehrmanntraut, R.; McMillan, S. 2007. Airspace design process for dynamic sectorisation. EUROCONTROL Exp. Centre, Bretigny sur Orge, November 2007.

Fron, X. 1998. ATM performance review in Europe, in The $2^{\text {nd }}$ USA/Europe ATM Seminar. Orlando, USA, December $1-4,1998$.

Heller, K. A.; Ghahramani, Z. 2005. Bayesian Hierarchical Clustering: Gatsby Unit Technical Report GCNU-TR 2005-002.

Kondroška, V.; Stankūnas, J. 2011. Lietuvos oro erdvès struktūros tobulinimas [Development of Lithuanian airspace structure], iš Aviacijos technologijos [Aviation Technologies]: 14-osios Lietuvos jaunuju mokslininku konferencijos "Mokslas - Lietuvos ateitis" $2011 \mathrm{~m}$. teminès konferencijos pranešimų medžiaga. Vilnius: Technika, 73-77.

Kondroška, V.; Stankūnas, J. 2012 [interaktyvus]. Oro eismo vadybos sistemos efektyvumo užtikrinimas regiono mastu
[Ensurance of ATM effectiveness at regional level], iš Aviacijos technologijos [Aviation Technologies]: 15-osios Lietuvos jaunuju mokslininku konferencijos „Mokslas - Lietuvos ateitis" $2012 \mathrm{~m}$. teminès konferencijos pranešimų medžiaga. Vilnius: Technika, 81-86. Prieiga per internetą [Available from Internet]: http://jmk.ai.vgtu.lt/index.php/ jmk_ai/jmkai15.

Kostiuk, P. F. 2001. Demand Management Versus Capacity Enhancement: Which Direction for Air Transportation? in The $4^{\text {th }}$ USA/Europe ATM R\&D Seminar. USA, Santa Fe. December 3-7, 2001.

Famanelli, D., T. 2005. A K-Partitioning Algorithm for Airspace Sectorization: Thesis. Italy: Padova University.

Liang, D.; Chin, D.K. 1998. CNS/ATM Enhancements to Reduce Aircraft Emissions, in The $2^{\text {nd }}$ USA/Europe ATM Seminar. Orlando, USA, December 1-4, 1998.

Mandal, S.; Overend, V. 1996. Assessment of capacity shortfall in the ECAC airspace through 2000-2015: UK NATS R\&D Report 9614

Manning, Ch. D.; Schütze, H. 1999. Foundations of Statistical Natural Language Processing. USA: MIT Press.

McCulloch, R. A. 1998. European and USA Operational Concepts for 2000-2010: A Framework for Comparison, in The $2^{\text {nd }}$ USA/Europe ATM Seminar. Orlando, USA, December $1-4,1998$.

Michalski, R.; Stepp, R. E.; Diday, E. 1981. A recent advance in data analysis: Clustering objects into classes characterized by conjunctive concepts, in L. Kanal, A. Rosenfeld. (Ed.) Progress in Pattern Recognition, vol. 1. Amsterdam: North-Holland Publishing Co.

Pomeret, J. M.; Mahlich, S. 1997. Piloting ATM through performance, in The $1^{\text {st }}$ USA/Europe ATM Seminar. Saclay, France, June 17-20, 1997.

Soler, M.; Olivares, A.; Staffetti, E. et al. 2011. En-route optimal flight planning constrained to pass through waypoints using MINLP, in The 9th USA/Europe ATM R\&D Seminar. Berlin, Germany, June 13-16, 2011.

Thompson, J. F.; Warsi, Z. U. A.; Mastin, C. W.1985. Numerical Grid Generation. Foundations and Applications. North-Holland.

Trandac, H.; Baptiste, P.; Duong, V. 2003. Optimized sectorization of airspace with constraints, in The 5th USA/Europe ATM R\&D Seminar. Budapest, Hungary, June 23-27, 2003.

Voss, W. R.; Hoffman, J. 2000. Analytical identification of airport and airspace capacity constraints, in The $3^{\text {rd }}$ USA/ Europe ATM Management R\&D Seminar. Napoli, Italy, June 13-16, 2000.

Weidner, T. J.; Green, S. 2000. Modelling ATM automation metering conformance benefits, in The $3^{\text {rd }}$ USA/Europe ATM Management R\&D Seminar. Napoli, Italy, June 13-16, 2000. 